

\section{Screening and modular pathway design for metabolic pathway optimization}

3 Jason T. Boock ${ }^{1}$, Apoorv Gupta ${ }^{2}$ and Kristala L. J. Prather ${ }^{1^{*}}$

4

$5{ }^{1}$ Department of Chemical Engineering, Massachusetts Institute of Technology,

6 Cambridge, MA 02142 USA

7 2Department of Biological Engineering, Massachusetts Institute of Technology,

8 Cambridge, MA 02142 USA

10 "Address correspondence to: Kristala L. J. Prather, Department of Chemical

11 Engineering, Massachusetts Institute of Technology, Cambridge, MA 02142 USA. Tel:

12 617-253-1950; Email: kljp@mit.edu

13

14

15

16

17

18

19

20 


\section{Abstract}

33 Biological conversion of substrate sugars to a variety of products such as acids and

34 alcohols is an increasingly popular option for chemical transformation due to its

35 generation of a variety of products with high specificity and because of significant

36 interest in the use of renewable feedstocks. However, pathway optimization through

37 metabolic engineering is often needed to make such molecules economically at a

38 relevant scale. Employing effective methods to search and narrow the immense

39 pathway parameter space is essential in order to meet performance metrics such as

40 high titer, yield and productivity with efficiency. This review focuses on two practices

41 that increase the likelihood of finding a more advantageous pathway solution:

42 implementing a screen to identify high producers and utilizing modular pathway design

43 to streamline engineering efforts. While screens seek to couple product titer with a

44 high-throughput measurement output, modular design aims to rationally construct

45 pathways to allow parallel optimization of various units. Both of these methodologies

46 have proven widely successful in metabolic engineering, with combinations of them

47 resulting in synergistic enhancements to pathway optimization. This review will

48 particularly highlight their utility for microbially derived acid and alcohol products, which

49 are of interest as fuels and value added products.

\section{Keywords}

53 Metabolic engineering, high-throughput screening, modular pathway design, free

54 fatty acid synthesis, microbial alcohol production, biosens 


\section{Introduction}

2 Biologically-derived alcohols and acids have a variety of uses, including as

3 biofuels, precursors for polymeric materials, food additives, cosmetics and fragrances.

4 The production scale of these molecules is currently highly varied [1], making them a

5 great class of compounds to be tackled by metabolic engineers, especially by looking

6 through past successes and failures. Moving products from laboratory-scale to

7 industrial-scale production requires pathway optimizations enabled by high-throughput

8 titer determination, identification of pathway bottlenecks, rational focusing of libraries,

9 and redesign of natural pathways. Screening technologies permit the user to sample a

10 larger parameter space by coupling a high-throughput readout (i.e. spectrophotometric,

11 fluorescence, cell sorting) with the final titer linked to the underlying genotype. Similarly,

12 modular design similarly can focus parameter space through rational design of

13 pathways to minimize the number of pathway architectures to be tested as well as to

14 optimize modules individually that may be later combined into a full pathway. As these

15 two techniques have become widely utilized, they can be adopted simultaneously to

16 further enhance the metabolic engineering process by allowing the exploration of

17 multiple modular orientations when a high-throughput screen is available or, conversely,

18 by focusing on pathway designs with a higher likelihood of success when screening is

19 limited (Figure 1).

\section{Screens}

22 The final number of pathway combinations or library members that can be feasibly

23 tested, or screened, limits the scope of an optimization study. Direct measurement of

24 product titer by gas or liquid chromatography analysis is low throughput (less that $10^{4}$

25 members) and falls at the bottom of the screening/selection ladder [2]. Higher

26 throughput screens in multiple micro-titer plates, on agar plates or by flow cytometry

27 require proper pairing of reporter molecules [3] and diversity generation [4] with

28 throughput size (Figure 1). It is imperative that the screen is coupled as closely with

29 desired metabolic output as possible, to avoid false-positives or cross-talk with other

30 endogenous cellular pathways. Additionally, throughput size should correlate with the

31 parameter space to be searched to avoid generically large screens that might not focus 
32 on the molecule of interest. In this section, we highlight screens for the biosynthesis of

33 acids (Table 1) and alcohols (Table 2) that span the throughput spectrum. This review

34 will mostly focus on screens that have led to increased acid or alcohol titers; however,

35 these methods have also been applied to many other biologically produced molecules,

36 which are thoroughly reviewed elsewhere [1,2].

Colorimetric and enzyme assays

39 Many successful metabolic engineering screens have been applied to the production of

40 colored compounds, such as carotenoids; however, neither acids nor alcohols can be

41 measured as easily due to low wavelength absorption. As such, it is necessary to

42 conjugate these compounds with dyes for visible or fluorescent detection. For instance,

43 Nile Red dye has been used as a non-specific label for fatty acids to quantify their

44 production $[5,6]$. When it is not possible to directly label the metabolic product,

45 quantification of enzyme activity may serve as a proxy for final titer. Nitroblue

46 tetrazolium was used to measure cellular NADH conversion to screen strain libraries for

47 members with increased ethanol and $n$-butanol production [7]. Similarly, monitoring

$48 \mathrm{NADH}$ or NADPH conversion enabled the engineering of a ketol-acid reductoisomerase

49 and an alcohol dehydrogenase, the two enzymes that utilize a reduced cofactor in the

50 pyruvate to isobutanol pathway $[8,9]$. Success in these enzyme-engineering

51 approaches was the result of both rationally designed protein libraries and a lower-

52 throughput screen $[8,9]$. In addition to enhancing enzyme activity and/or specificity,

53 feedback inhibition can also be targeted. Insensitivity to CoA-SH was engineered into a

54 thiolase enzyme, which condenses two acetyl-CoA molecules at the beginning of the

55 fatty acid elongation pathway, by measuring NADPH consumption, resulting in an

56 overall cellular increase in $n$-butanol titer [10] $\bullet$.

58 Biosensors

59 Although direct measurement of product titer is ultimately a requirement of metabolic

60 engineering studies, it is the lowest throughput measurement method. It is also difficult

61 to find chemical probes to directly quantify in vivo production. Biosensors couple the

62 detection of a desired product with the expression of a reporter gene [3]. Such screens 
63 are advantageous because they allow for concentration-dependent, rapid, specific and

64 intracellular measurement of compounds, including difficult-to-monitor pathway

65 intermediates. Additionally, well-designed biosensors, after being used to screen

66 production, can be incorporated as part of a metabolic control network for dynamic flux

67 control. Many natural biosensors exist for exactly this reason and others are currently

68 being developed to bind to compounds of interest in heterologous hosts [3].

69 Biosensors that act via transcriptional regulation are heavily utilized since they

70 directly couple product sensing with gene transcription and thus have been the most

71 successful biosensors to date. FadR is a naturally-occurring transcriptional regulatory

72 protein that binds fatty acids. The FadR operator binding region was tuned to detect

73 various concentrations of free fatty acids and was used to regulate their production by

74 controlling the expression of downstream pathway enzymes [11]. FapR is a regulatory

75 protein that interacts with malonyl-CoA, an intermediate in fatty acid synthesis. By

76 monitoring the production of the malonyl-CoA intermediate, $\mathrm{Xu}$ and coworkers were

77 able to toggle between synthesis of an upstream pathway intermediate and final free

78 fatty acid product (Figure 2) [12] ••. Additionally, the binding kinetics of FapR have

79 been modeled for future use in producing malonyl-CoA-derived compounds [13].

80 Natural sensors also exist for the detection of alcohols. The transcription factor

81 BmoR binds $n$-butanol and was used to screen ribosome binding site (RBS) libraries,

82 resulting in a $35 \%$ increase in $n$-butanol titer by controlling expression of pathway

83 enzymes [14] •. Importantly, it was found that the BmoR protein does not bind ethanol,

84 which is a major byproduct, resulting in low crosstalk in vivo [14] •. As mentioned

85 earlier, monitoring NADH or NADPH consumption can be used to measure enzyme

86 catalysis when a product is difficult to detect. The SoxR transcription factor binds

$87 \quad \mathrm{NADPH}$ and was used to report its intracellular concentration when an alcohol

88 dehydrogenase was overexpressed [15]. While monitoring the reducing power of cells

89 is useful since it is generally applicable to the optimization of numerous pathways, it is

90 also subject to high crosstalk with other endogenous pathways that utilize NADH or

91 NADPH [15].

92 It is worth noting that there are several other attractive biosensor designs that

93 have yet to be applied to screening acid or alcohol production. RNA-based sensors are 
94 especially interesting due to their modular design, our in-depth understanding of their

95 binding/folding properties, and their ease of implementation as transcriptional or

96 translational regulators. Two noteworthy studies include an RNA switch that measures

97 theophyline production [16], and a riboswitch that binds to glucosamine 6-phosphate

98 that can be diversified with other aptamers [17]. Rational modification of existing

99 transcription factors with new specificities is especially attractive and has already been

100 accomplished with an arabinose-binding transcription factor [18]. Lastly, little attention

101 has been paid to sensing without the need for a transcriptional reporter. Engineering

102 allosteric enzymes by transferring regulatory domains may make this possible [19] as

103 well as allow future pathway regulation at the enzyme level to eliminate wasteful and

104 unnecessary transcription and translation.

105

106

Growth and single-cell screens

107 Growth-based screens have also been used for the optimization of engineered

108 pathways for acid and alcohol production. These screens couple substrate utilization,

109 product formation and product/intermediate tolerance with growth rate, giving a

110 complete picture of how the organism will perform the desired conversion. Growth

111 screens are typically lower throughput than biosensor-based ones since each construct

112 is usually cultured separately in a micro-titer plate or on solid media. Utilization of

113 cellobiose for the production of ethanol in yeast was enhanced by optimizing the cellular

114 uptake of the glucose polymer and by improving enzymatic conversion, resulting in

115 increased cell growth [20]. Improvements in xylose consumption and ethanol

116 production were achieved by a combinatorial engineering strategy that used

117 homologous enzymes and different yeast strains as part of a growth screen. [21].

118 Large-scale genomic libraries have been assessed for roles in ethanol tolerance by

119 coupling them with a growth screen [22]. Similar gains in tolerance have been found by

120 transcription factor mutagenesis coupled with a growth screen in both ethanol and

121 glucose to simultaneously test substrate utilization and product tolerance [23]. Global

122 regulator engineering has also been attempted using acid shock screening to improve

123 low pH tolerance [24]. 
Whole-cell biosensors that couple an auxotrophic strain with synthesis of a

125 molecule of interest are an attractive screen or selection due to their holistic

126 consideration of cellular metabolism and high-throughput nature. One of the most

127 successful uses of a whole-cell biosensor involved creation of an auxotrophic strain for

128 two pathway intermediates, isopentenyl pyrophosphate or dimethylallyl pyrophosphate;

129 only upon their supplementation through pathway addition could enhanced producers of

130 mevalonate grow [25]. To determine appropriate knockouts for a pathway of interest,

131 computational prediction of auxotrophic strains can be used [26]. In addition to

132 rationally designed auxotrophic strains, others have isolated auxotrophic organisms for

133 specific compounds of interest from environmental samples; for example, organisms

134 that are auxotrophic for thiamine can be used to overproduce alpha-ketoglutaric acid

135 [27]. Although using auxotrophs for metabolic engineering has proven effective in

136 increasing product titers, single-cell measurements aim to greatly increase throughput

137 and can be generally applied to many products. Monitoring the metabolism of single-

138 cells in microfluidic devices has been used to screen for optimized lactate production

139 and xylose consumption [28] • Automated measurement of pathway flux using ${ }^{13} \mathrm{C}$

140 labeling and NMR analysis could provide great detail for pathway optimization while

141 being globally applicable with limited researcher time needed [29].

\section{Modular design}

144 Screening for metabolic product formation is a powerful tool in metabolic engineering,

145 often leading to substantial increases in titer. However, many screens do not directly

146 report the final titer for a molecule of interest leading to false-positive solutions, or they

147 may be too difficult to implement (i.e. it may be more time consuming to design a

148 biosensor for a pathway rather than to simply perform chromatographic analysis). For

149 these reasons, it is useful to apply other constraints, such as modular design, when

150 searching parameter space to increase the likelihood of obtaining an optimal solution.

151 Modular pathway engineering gained attention in 2010 with its use in increasing taxol

152 production [30] and was further described in the following review [31]. Modular design

153 is generally defined as grouping pathway enzymes elements together into modules with

154 the purpose of easing pathway construction and balancing pathway enzyme expression 
155 to control flux. To create a modular pathway, the enzymes are often grouped into 156 expression cassettes under the control of different promoters and/or are separated on

157 multiple plasmids. Additionally, depending on pathway design, modular construction

158 can permit the independent optimization of pathway modules by directly feeding and

159 sampling each unit (Figure 1). Other pathway optimization strategies that are often

160 used in conjunction with modular design include: plasmid copy number control,

161 promoter design, ribosome binding site tuning and post-translational modification [32].

162 This section of our review will focus on the modular construction of pathways for acid

163 (Table 1) and alcohol (Table 2) production; an excellent and thorough review covering

164 other ways of implementing modular construction and its role in producing alternative

165 compounds is also available [33].

166 Microbially derived fatty acid chemicals have applications as biodiesel,

167 surfactants and cosmetic products [34]. Pathway engineering has been explored in

168 various scenarios including the deletion of the $\beta$-oxidation pathway (Figure 2) eycle [35]

169 and then the implementation of the reverse $\beta$-oxidation cycle (Figure 3) [36]. In addition

170 to high final titers for free fatty acids, specific control of chain length is desired to create

171 a homogeneous product. Tseng and coworkers created a three module pathway

172 (precursor, up and downstream) to produce short odd-chain fatty acids [37]. The

173 functionality of each module was verified independently to focus on optimal designs for

174 the final full pathway, and precursor supply was dictated to control final product length

175 [37] . Another successful engineering approach also divided fatty acid synthesis into

176 three modules and found that by varying plasmid copy number, followed by RBS tuning

177 and bioreactor optimization, titers of fatty acids greater than $8.6 \mathrm{~g} / \mathrm{L}$ could be obtained

178 (Figure 3a) [6] ••. Combining modular design with a molecular sensor for an

179 intermediate in fatty acid synthesis, Xu, Koffas and coworkers could oscillate between a

180 source and sink for malonyl-CoA to slightly increase free fatty acid production (Figure

181 2) [12] ••. Similarly, the FadR transcription factor was used to control the final two

182 modules of fatty acid synthesis so that these enzymes were only expressed when the

183 intermediate pool was sufficiently high [11]. In another interesting study, fatty acid chain

184 length was programmed through both targeted enzyme degradation and mutation to an

185 auxiliary elongation enzyme [38]. The amount of the elongation enzyme FabB was 
186 controlled by targeted protein degradation to limit the chain length of the resulting fatty 187 acids [38].

188 In addition to fatty acids, production of alcohols has also taken advantage of 189 modular pathway design (Table 2). Many of the $\mathrm{C}_{4}-\mathrm{C}_{5}$ chain alcohols currently 190 produced from microbes are derived from amino acid synthesis [39], while longer chains 191 are enabled by manipulation of the $\beta$-oxidation pathway [35] or use of the reverse $\beta$ 192 oxidation cycle [36]. Extension of the carbon chain length using the cyclic beginning of 193 the leucine biosynthesis pathway combined with rational enzyme mutagenesis enabled 194 the production of longer-chained and branched alcohols $\left(\mathrm{C}_{4}-\mathrm{C}_{8}\right)[40,41]$; however, each 195 iteration through the pathway is carbon wasteful and it does not generate a 196 homogeneous product [41]. In a study by Sheppard and coworkers, they created a 197 pathway for the specific production of isohexanol consisting of four modules, including a 198 CoA-dependent reverse $\beta$-oxidation and amino acid precursor synthesis modules 199 (Figure 3b) [42] ••. Modular design allowed for independent optimization of the four 200 units of the pathway using homologous enzymes as well as permitted the exploration of 201 specificity to reduce undesired byproduct formation [42] ••. In Bacillus subtilis, it was 202 found that isobutanol production was increased by $60 \%$ using a native promoter in front 203 of an upstream module and a strong promoter to control downstream enzyme 204 expression [43]. Improved fatty alcohol yields were obtained by balancing the 205 expression of a three-enzyme pathway as well as by using a solvent layer 206 simultaneously to extract the alcohols [44]. In addition to increasing productivity, 207 specific control of chain length for fatty alcohols was possible by adding different 208 thioesterases to a downstream module [45]. Controlled chain length of dicarboxcylic 209 acids $\left(\mathrm{C}_{6}, \mathrm{C}_{8}\right.$, and $\left.\mathrm{C}_{10}\right)$ was obtained using different enzyme combinations in the 210 iterative reverse $\beta$-oxidation cycle module (incorporated into the $E$. coli genome) and a 211 downstream $\omega$-oxidation module [46]. Using a $\beta$-oxidation knockout, it was possible to 212 produce a variety of fatty acid short-chain esters through a combination of modules for

213 fatty acid synthesis and 2-keto acid conversion to short chain alcohols [47].

214 Modular pathway design has proven its place in metabolic engineering; however,

215 its potential is far from achieved as outlined in the following reviews $[33,48]$.

216 Combination with other approaches to pathway engineering may enable additional 
217 significant advances. Orthogonal T7 polymerases have been created which would 218 permit high level production of multiple modules as well as separation of the sensing 219 logic module from the functional module expression [49]. An autonomous controller

220 module was developed using quorum sensing to successfully increase the production of

221 1,4-butandiol from a de novo designed pathway [50] •. Additionally, this work

222 successfully decoupled cell growth from the production module by using two different

223 carbon sources and introducing knockouts between the pentose phosphate pathway

224 and glycolysis [50] • Design of modular architecture has been limited to separating

225 linear pathways at specific sampling or branch points. Using an unbiased network

226 approach, it may be possible to rethink the network architecture used in modular design

227 [51]. Additionally, systems biology can predict other non-canonical pathways to be

228 included in modular design and whose crosstalk may affect specificity and yield [52].

229 Lastly, kinetic incorporation within modular pathway design must be considered beyond

230 varying plasmid copy number and RBS tuning. Grouping enzymes into modules based

231 on catalytic turnover is a logical next step [33]. Computational prediction of module

232 outputs (i.e. through ensemble modeling) could further constrain modular pathway

233 design to create constructs with the highest likelihood of success [53].

234

235 Future directions

236 Screens and modular pathway design can increase the likelihood of finding optimal

237 metabolic solutions for the production of many compounds of interest. While modular

238 design outlines general rules for how to construct pathways, screens and selections are

239 often specific for only one molecule, thus requiring redesign before being applied to

240 other pathways. Future studies will look to find global screens to limit the amount of

241 optimization that must occur for a single pathway. For instance, Lee, Dueber and

242 coworkers have created a general methodology for optimizing a pathway without the

243 need for a high throughput screen [54] •. They used computational modeling to

244 determine optimal expression levels for a three-enzyme pathway and verified their

245 design by measuring the production of fluorescent proteins prior to testing their pathway

246 with desired enzymes [54] •. The synergy of auxiliary pathways (i.e. generation of

247 reducing equivalents, intermediate cofactors, ATP) with a pathway of interest must be 
considered to achieve an overall balanced system [31,55]. This has led to the

249 modularization of several of these pathways resulting in an increased yield of $n$ -

250 propanol [55] and could be easily applied to the synthesis of other molecules of interest.

251 As evidenced herein, pathway engineering combined with screening

252 methodologies enables a narrowing of the parameter space to be searched to

253 determine a more optimal pathway solution. Similarly, the expansive data sets available

254 from next-generation sequencing technologies can provide great insight into pathway

255 design, from enzyme choice to expression level, to further focus the explored parameter

256 space. Genomic sequencing data along with the characterization of the fermentation

257 products for yeast strains has been used to find the traits that matter most for ethanol

258 production [56]. Similarly, RNAseq was performed on a variety of yeast strains to

259 determine their response to different substrates, revealing a common set of differentially

260 regulated genes [57]. The assembly of metagenomes from an environmental pool of

261 organisms has identified species that overproduce ethanol as well as the pathways

262 responsible for this trait [58]. Genomic sequencing and annotation of thermophilic

263 organisms have led to discovery of enzymes that have or maintain increased activity at

264 high temperatures. These enzymes were then used to enhance cellobiose conversion

265 to $n$-butanol at elevated temperatures in a thermophilic bacterium [59]. Finding

266 orthogonal pathways for the production of fatty acids and expression of these

267 complexes in heterologous hosts has the potential to alter the specificity of production

268 and could be more beneficial than mutating native machinery [60]. Thus, genome-scale

269 techniques, enabled by high-throughput sequencing and data set comparisons, permit

270 users to not only identify high titer producers, but also gain foundational insight into the

271 biological traits and principles that lead to these favorable phenotypes.

272

273 Acknowledgements

274 We thank Yekaterina Tarasova for helpful edits to the manuscript. This work was

275 supported by the National Science Foundation (Graduate Research Fellowship to A.G.;

276 Synthetic Biology Engineering Research Center (SynBERC), Grant EEC-0540879), the

277 US Department of Energy (Grant No. DE-SC0012555), and the Institute for

278 Collaborative Biotechnologies through Grant W911NF-09-0001 from the U.S. Army 
279 Research Office. The content of the information does not necessarily reflect the position 280 or the policy of the Government, and no official endorsement should be inferred.

281

282

283

284 
1. Sun J, Alper HS: Metabolic engineering of strains: from industrial-scale to lab-scale chemical production. J Ind Microbiol Biotechnol 2015, 42:423-436.

2. Dietrich JA, McKee AE, Keasling JD: High-throughput metabolic engineering: advances in small-molecule screening and selection. Annu Rev Biochem 2010, 79:563-590.

3. Eggeling L, Bott M, Marienhagen J: Novel screening methods-biosensors. Curr Opin Biotechnol 2015, 35C:30-36.

4. Liu W, Jiang R: Combinatorial and high-throughput screening approaches for strain engineering. Appl Microbiol Biotechnol 2015, 99:2093-2104.

5. Hoover SW, Youngquist JT, Angart PA, Withers ST, Lennen RM, Pfleger BF: Isolation of improved free fatty acid overproducing strains of Escherichia coli via nile red based high-throughput screening. Environ Prog \& Sust Energy 2012, 31:17-23.

6. Xu P, Gu Q, Wang W, Wong L, Bower AG, Collins CH, Koffas MA: Modular optimization of multi-gene pathways for fatty acids production in E. coli. Nat Commun 2013, 4:1409.

7. Scheel M, Lutke-Eversloh T: New options to engineer biofuel microbes: development and application of a high-throughput screening system. Metab Eng 2013, 17:5158.

8. Bastian S, Liu X, Meyerowitz JT, Snow CD, Chen MM, Arnold FH: Engineered ketol-acid reductoisomerase and alcohol dehydrogenase enable anaerobic 2methylpropan-1-ol production at theoretical yield in Escherichia coli. Metab Eng 2011, 13:345-352.

9. Liu X, Bastian S, Snow CD, Brustad EM, Saleski TE, Xu JH, Meinhold P, Arnold FH: Structure-guided engineering of Lactococcus lactis alcohol dehydrogenase LlAdhA for improved conversion of isobutyraldehyde to isobutanol. $J$ Biotechnol 2012, 164:188-195.

10. Mann MS, Lutke-Eversloh T: Thiolase engineering for enhanced butanol production in Clostridium acetobutylicum. Biotechnol Bioeng 2013, 110:887-897.

11. Zhang F, Carothers JM, Keasling JD: Design of a dynamic sensor-regulator system for production of chemicals and fuels derived from fatty acids. Nat Biotechnol 2012, 30:354-359.

12. Xu P, Li L, Zhang F, Stephanopoulos G, Koffas M: Improving fatty acids production by engineering dynamic pathway regulation and metabolic control. Proc Natl Acad Sci 2014, 111:11299-11304.

13. Feher T, Libis V, Carbonell P, Faulon JL: A sense of balance: experimental investigation and modeling of a malonyl-CoA sensor in Escherichia coli. Front Bioeng Biotechnol 2015, 3:46.

14. Dietrich JA, Shis DL, Alikhani A, Keasling JD: Transcription factor-based screens and synthetic selections for microbial small-molecule biosynthesis. ACS Synth Biol 2013, 2:47-58.

15. Siedler S, Schendzielorz G, Binder S, Eggeling L, Bringer S, Bott M: SoxR as a single-cell Biosensor for NADPH-consuming enzymes in Escherichia coli. ACS Synth Biol 2014, 3:41-47.

16. Michener JK, Smolke CD: High-throughput enzyme evolution in Saccharomyces cerevisiae using a synthetic RNA switch. Metab Eng 2012, 14:306-316. 
17. Lee SW, Oh MK: A synthetic suicide riboswitch for the high-throughput screening of metabolite production in Saccharomyces cerevisiae. Metab Eng 2015, 28:143150.

18. Tang SY, Qian S, Akinterinwa O, Frei CS, Gredell JA, Cirino PC: Screening for enhanced triacetic acid lactone production by recombinant Escherichia coli expressing a designed triacetic acid lactone reporter. J Am Chem Soc 2013, 135:10099-10103.

19. Cross PJ, Allison TM, Dobson RC, Jameson GB, Parker EJ: Engineering allosteric control to an unregulated enzyme by transfer of a regulatory domain. Proc Natl Acad Sci 2013, 110:2111-2116.

20. Eriksen DT, Hsieh PC, Lynn P, Zhao H: Directed evolution of a cellobiose utilization pathway in Saccharomyces cerevisiae by simultaneously engineering multiple proteins. Microb Cell Fact 2013, 12:61.

21. Kim B, Du J, Eriksen DT, Zhao H: Combinatorial design of a highly efficient xyloseutilizing pathway in Saccharomyces cerevisiae for the production of cellulosic biofuels. Appl Environ Microbiol 2013, 79:931-941.

22. Woodruff LB, Boyle NR, Gill RT: Engineering improved ethanol production in Escherichia coli with a genome-wide approach. Metab Eng 2013, 17:1-11.

23. Alper H, Moxley J, Nevoigt E, Fink GR, Stephanopoulos G: Engineering yeast transcription machinery for improved ethanol tolerance and production. Science 2006, 314:1565-1568.

24. Basak S, Geng H, Jiang R: Rewiring global regulator cAMP receptor protein (CRP) to improve E. coli tolerance towards low pH.J Biotechnol 2014, 173:68-75.

25. Pfleger BF, Pitera DJ, Newman JD, Martin VJ, Keasling JD: Microbial sensors for small molecules: development of a mevalonate biosensor. Metab Eng 2007, 9:30-38.

26. Tepper N, Shlomi T: Computational design of auxotrophy-dependent microbial biosensors for combinatorial metabolic engineering experiments. PLoS One 2011, 6:e16274.

27. Zhou J, Zhou H, Du G, Liu L, Chen J: Screening of a thiamine-auxotrophic yeast for alpha-ketoglutaric acid overproduction. Lett Appl Microbiol 2010, 51:264-271.

28. Wang BL, Ghaderi A, Zhou H, Agresti J, Weitz DA, Fink GR, Stephanopoulos G: Microfluidic high-throughput culturing of single cells for selection based on extracellular metabolite production or consumption. Nat Biotechnol 2014, 32:473-478.

29. Heux S, Poinot J, Massou S, Sokol S, Portais JC: A novel platform for automated highthroughput fluxome profiling of metabolic variants. Metab Eng 2014, 25:8-19.

30. Ajikumar PK, Xiao WH, Tyo KE, Wang Y, Simeon F, Leonard E, Mucha O, Phon TH, Pfeifer B, Stephanopoulos G: Isoprenoid pathway optimization for Taxol precursor overproduction in Escherichia coli. Science 2010, 330:70-74.

31. Yadav VG, De Mey M, Lim CG, Ajikumar PK, Stephanopoulos G: The future of metabolic engineering and synthetic biology: towards a systematic practice. Metab Eng 2012, 14:233-241.

32. Jones JA, Toparlak OD, Koffas MA: Metabolic pathway balancing and its role in the production of biofuels and chemicals. Curr Opin Biotechnol 2014, 33:52-59.

33. Biggs BW, De Paepe B, Santos CNS, De Mey M, Ajikumar PK: Multivariate modular metabolic engineering for pathway and strain optimization. Curr Opin Biotechnol 2014, 29:156-162. 
34. Pfleger BF, Gossing M, Nielsen J: Metabolic engineering strategies for microbial synthesis of oleochemicals. Metab Eng 2015, 29:1-11.

35. Steen EJ, Kang Y, Bokinsky G, Hu Z, Schirmer A, McClure A, Del Cardayre SB, Keasling JD: Microbial production of fatty-acid-derived fuels and chemicals from plant biomass. Nature 2010, 463:559-562.

36. Dellomonaco C, Clomburg JM, Miller EN, Gonzalez R: Engineered reversal of the betaoxidation cycle for the synthesis of fuels and chemicals. Nature 2011, 476:355359.

37. Tseng HC, Prather KL: Controlled biosynthesis of odd-chain fuels and chemicals via engineered modular metabolic pathways. Proc Natl Acad Sci 2012, 109:1792517930.

38. Torella JP, Ford TJ, Kim SN, Chen AM, Way JC, Silver PA: Tailored fatty acid synthesis via dynamic control of fatty acid elongation. Proc Natl Acad Sci U S A 2013, 110:11290-11295.

39. Atsumi S, Hanai T, Liao JC: Non-fermentative pathways for synthesis of branchedchain higher alcohols as biofuels. Nature 2008, 451:86-89.

40. Zhang K, Sawaya MR, Eisenberg DS, Liao JC: Expanding metabolism for biosynthesis of nonnatural alcohols. Proc Natl Acad Sci 2008, 105:20653-20658.

41. Marcheschi RJ, Li H, Zhang K, Noey EL, Kim S, Chaubey A, Houk KN, Liao JC: A synthetic recursive "+1" pathway for carbon chain elongation. ACS Chem Biol 2012, 7:689697.

42. Sheppard MJ, Kunjapur AM, Wenck SJ, Prather KL: Retro-biosynthetic screening of a modular pathway design achieves selective route for microbial synthesis of 4methyl-pentanol. Nat Commun 2014, 5:5031.

43. Li S, Jia X, Wen J: Improved 2-methyl-1-propanol production in an engineered Bacillus subtilis by constructing inducible pathways. Biotechnol Lett 2012, 34:2253-2258.

44. Youngquist JT, Schumacher MH, Rose JP, Raines TC, Politz MC, Copeland MF, Pfleger BF: Production of medium chain length fatty alcohols from glucose in Escherichia coli. Metab Eng 2013, 20:177-186.

45. Cao YX, Xiao WH, Liu D, Zhang JL, Ding MZ, Yuan YJ: Biosynthesis of odd-chain fatty alcohols in Escherichia coli. Metab Eng 2015, 29:113-123.

46. Clomburg JM, Blankschien MD, Vick JE, Chou A, Kim S, Gonzalez R: Integrated engineering of beta-oxidation reversal and omega-oxidation pathways for the synthesis of medium chain omega-functionalized carboxylic acids. Metab Eng 2015, 28:202-212.

47. Guo D, Zhu J, Deng Z, Liu T: Metabolic engineering of Escherichia coli for production of fatty acid short-chain esters through combination of the fatty acid and 2keto acid pathways. Metab Eng 2014, 22:69-75.

48. Kittleson JT, Wu GC, Anderson JC: Successes and failures in modular genetic engineering. Curr Opin Chem Biol 2012, 16:329-336.

49. Temme K, Hill R, Segall-Shapiro TH, Moser F, Voigt CA: Modular control of multiple pathways using engineered orthogonal T7 polymerases. Nucleic Acids Res 2012, 40:8773-8781.

50. Liu H, Lu T: Autonomous production of 1,4-butanediol via a de novo biosynthesis pathway in engineered Escherichia coli. Metab Eng 2015, 29:135-141. 
51. Papin JA, Reed JL, Palsson BO: Hierarchical thinking in network biology: the unbiased modularization of biochemical networks. Trends Biochem Sci 2004, 29:641-647.

52. Bordbar A, Nagarajan H, Lewis NE, Latif H, Ebrahim A, Federowicz S, Schellenberger J, Palsson BO: Minimal metabolic pathway structure is consistent with associated biomolecular interactions. Mol Syst Biol 2014, 10:737.

53. Link H, Christodoulou D, Sauer U: Advancing metabolic models with kinetic information. Curr Opin Biotechnol 2014, 29:8-14.

54. Lee ME, Aswani A, Han AS, Tomlin CJ, Dueber JE: Expression-level optimization of a multi-enzyme pathway in the absence of a high-throughput assay. Nucleic Acids Res 2013, 41:10668-10678.

55. Shen CR, Liao JC: Synergy as design principle for metabolic engineering of 1propanol production in Escherichia coli. Metab Eng 2013, 17:12-22.

56. Hubmann G, Foulquie-Moreno MR, Nevoigt E, Duitama J, Meurens N, Pais TM, Mathe L, Saerens S, Nguyen HT, Swinnen S, et al.: Quantitative trait analysis of yeast biodiversity yields novel gene tools for metabolic engineering. Metab Eng 2013, 17:68-81.

57. Feng $\mathrm{X}$, Zhao $\mathrm{H}$ : Investigating host dependence of xylose utilization in recombinant Saccharomyces cerevisiae strains using RNA-seq analysis. Biotechnol Biofuels 2013, 6:96.

58. Carere CR, Rydzak T, Verbeke TJ, Cicek N, Levin DB, Sparling R: Linking genome content to biofuel production yields: a meta-analysis of major catabolic pathways among select $\mathrm{H} 2$ and ethanol-producing bacteria. BMC Microbiol 2012, 12:295.

59. Lin PP, Rabe KS, Takasumi JL, Kadisch M, Arnold FH, Liao JC: Isobutanol production at elevated temperatures in thermophilic Geobacillus thermoglucosidasius. Metab Eng 2014, 24:1-8.

60. Haushalter RW, Groff D, Deutsch S, The L, Chavkin TA, Brunner SF, Katz L, Keasling JD: Development of an orthogonal fatty acid biosynthesis system in $E$. coli for oleochemical production. Metab Eng 2015, 30:1-6. 


\section{Annotated references}

•• [6] The authors used modular design to split a 15-enzyme pathway amongst three plasmids and found that varying copy numbers for the modules gave rise to a more optimal solution than placing all the enzymes on high copy plasmids.

- [10] This manuscript reports a clever extension of a NADPH consumption assay for thiolase activity by including the CoA-SH product to find variants that are feedback insensitive.

- [12] This manuscripts describes an outstanding integration of a biosensor with modular pathway architecture. The authors used the sensing of a pathway intermediate to oscillate between an up and downstream module to create two production modes for the pathway.

- [14] The authors report an excellent use of a biosensor to find an optimal pathway solution from a large RBS library as well as a detailed exploration of crosstalk for nondesired molecules.

- [28] This manuscript reports a novel approach to a single-cell screening using a microfluidic device to measure substrate consumption and product generation in a highthroughput manner.

-• [42] The manuscript describes an inventive combination of a portion of amino acid synthesis with the reverse $\beta$-oxidation pathway to produce a non-natural, branched alcohol. The authors used modular design to facilitate pathway construction and individually validate modules prior to assembling the entire pathway.

- [50] The authors used genetic knockouts to successfully decouple glucose consumption for cellular growth and xylose utilization for 1,4-butanediol production.

- [54] The authors report a modular strategy that can be adapted to numerous pathway architectures based on metabolic modeling and validated by fluorescent protein expression. 


\section{Figure legends}

\section{Figure 1}

This schematic describes the necessary inputs to successfully implement a screen or design a modular pathway as well as the general outcomes of each. Screens are characterized by their high-throughput nature and can be divided into three classes: colorimetric/enzymatic, biosensors, or growth-based. Colorimetric/enzymatic screens result from the labeling of a final product for high throughput detection or by coupling an in vitro assay of enzyme activity with a product titer. Biosensors often act through transcriptional regulation, permitting the concentration-dependent expression of a reporter gene as a result of metabolic production. Growth screens couple the generation of product with growth rate to find strains with increased substrate uptake and conversion. Modular design is an attractive engineering choice when a highthroughput screen is not available by limiting the architectures tested using rational pathway construction. Modular design permits easy pathway assembly with the purpose of balancing enzyme production as well as enabling parallel optimization of modules through intermediate sampling/feeding to limit the number of final pathway designs to test. In the future, combining modular design with a high-throughput screen would allow for more pathway architectures to be explored with the purpose of finding general design rules to be applied to a variety of pathways of interest.

\section{Figure 2}

In [12], synthesis of free fatty acids from glucose was divided into two modules: an acetyl-CoA activation module (ACA) that resulted in the synthesis of malonyl-CoA from glucose (upstream module, green) and a free fatty acid synthesis module (FAS, pink) that converted malonyl-CoA into free fatty acids (downstream module). In addition to the overexpressed pathway enzymes, several endogenous enzymes are necessary to convert glucose to free fatty acids; these pathways are indicated by dotted lines. Natural $\beta$-oxidation was knocked out using a deletion of fadD. Expression of enzymes from the two modules was transcriptionally regulated by FapR, an intracellular transcription factor responsive to malonyl-CoA concentration. FapR can act as a repressor or activator depending on the promoters used and number of fapO sites present in gene expression cassettes. The upstream ACA module was activated by FapR while the downstream FAS module was repressed. Increasing concentrations of malonyl-CoA over culture time resulted in deactivation of the upstream module and derepression of the downstream module, allowing the cell to toggle between the two modules to better utilize cellular resources.

\section{Figure 3}

A) In [6], conversion of glucose to free fatty acids was split into three modules, a glycolysis module (Gly, blue) that consisted of selected genes from glycolytic pathways, an acetyl-CoA activation module (ACA, green) that contained genes responsible for the 
conversion of acetyl-CoA into malonyl-CoA, and a fatty acid synthesis module (FAS,

48 pink) with genes to convert malonyl-CoA into free fatty acids. Endogenous pathways

49 are indicated by dotted lines. For each module, the genes were present in a pseudo-

50 operon where a promoter was placed directly before each gene but only a single

51 terminator was present downstream. The pseudo-operons were expressed from

52 plasmids that contained a high, medium, and/or low copy number origin of replication,

53 permitting the exploration of module expression level on free fatty acid production. The

54 optimal set of origins of replication is boxed. B) In [42], synthesis of isohexanol from

55 glucose was implemented through a four-module pathway, which included valine

56 synthesis (module 1, purple), acetyl-CoA activation (module 2, green), reverse $\beta$ -

57 oxidation cycle (module 3, pink), and acid reduction (module 4, red). An endogenous

58 thioesterase was used to terminate the reverse $\beta$-oxidation cycle. Modular design

59 permitted the parallel characterization of several of the pathway elements.

60 Characterization of the substrate specificity of the carboxcylic reductase $\left(\mathrm{Car}_{\mathrm{Ni}}\right)$ in

61 module 4 enabled the de novo construction of upstream pathway elements to

62 synthesize the desired substrate, isohexanoate. By feeding the isobutyrate

63 intermediate to cells that contained modules 2 and 3, combinations of homologous Ter

64 and PhaJ enzymes were tested to identify combinations that produced the highest

65 isohexanoate titers (boxed). Modular design aided in separating different parts of the

66 synthesis pathway so each module could be improved and tested separately, by feeding

67 appropriate substrates and screening for corresponding products. 
Table 1: Free fatty acid production

\begin{tabular}{|c|c|c|c|c|c|c|}
\hline Fatty acid & $\begin{array}{l}\text { Engineering } \\
\text { approach }\end{array}$ & Titer $^{1}$ (g/L) & Yield $^{2}$ & $\begin{array}{c}\text { Fold } \\
\text { improve } \\
\text { ment }^{3}\end{array}$ & $\begin{array}{c}\text { Library } \\
\text { members } \\
\text { screened (\#) }\end{array}$ & Reference \\
\hline Pentanoate & $\begin{array}{l}\text { Modular } \\
\text { design, } \\
\text { precursor } \\
\text { feeding }\end{array}$ & 0.40 & $0.04 \mathrm{~g} / \mathrm{g}_{\mathrm{gly}}$ & $\mathrm{n} / \mathrm{a}$ & 37 & [37] \\
\hline Octanoate ${ }^{4}$ & $\begin{array}{l}\text { Dynamic } \\
\text { regulation }\end{array}$ & 0.26 & $\begin{array}{l}0.052 \\
\mathrm{~g} / \mathrm{g}_{\mathrm{gly}}\end{array}$ & 1.32 & 6 & [38] \\
\hline $\begin{array}{l}\mathrm{C}_{12}, \mathrm{C}_{14}, \mathrm{C}_{16}, \\
\mathrm{C}_{18} \text { free fatty } \\
\text { acids }\end{array}$ & $\begin{array}{l}\text { Colorimetric } \\
\text { screen, } \\
\text { transposon } \\
\text { library }\end{array}$ & 0.89 & $\begin{array}{l}0.223 \\
g / g_{\text {gly }}\end{array}$ & 1.2 & 2786 & [5] \\
\hline $\begin{array}{l}\mathrm{C}_{12}-\mathrm{C}_{20} \\
\text { free fatty } \\
\text { acids }\end{array}$ & $\begin{array}{l}\text { Biosensor, } \\
\text { modular } \\
\text { design, } \\
\text { promoter } \\
\text { engineering }\end{array}$ & 1.5 & $\begin{array}{l}0.075 \\
\text { g/g gluc }\end{array}$ & 3.51 & 20 & {$[11]$} \\
\hline $\begin{array}{l}\mathrm{C}_{14}, \mathrm{C}_{16}, \mathrm{C}_{18} \\
\text { free fatty } \\
\text { acids }^{5}\end{array}$ & $\begin{array}{l}\text { Modular } \\
\text { design, plasmid } \\
\text { copy number, } \\
\text { RBS tuning }\end{array}$ & 2.04 & $\begin{array}{l}0.255 \\
g / g_{\text {gluc }}\end{array}$ & $3.46^{6}$ & 17 & {$[6] \bullet \bullet$} \\
\hline $\begin{array}{c}\mathrm{C}_{14}, \mathrm{C}_{16}, \mathrm{C}_{18} \\
\text { free fatty } \\
\text { acids }^{5}\end{array}$ & $\begin{array}{c}\text { Biosensor, } \\
\text { modular design }\end{array}$ & 3.86 & $\begin{array}{l}0.193 \\
\text { g/g gluc }\end{array}$ & 3.1 & 4 & {$[12] \bullet \bullet$} \\
\hline
\end{tabular}

${ }^{1}$ Titers reported from experiments conducted under screening/small-scale conditions. In some cases, higher titers were achieved by scaling-up to bioreactors.

${ }^{2}$ Yields were calculated from titers reported in this table and substrate amounts listed in the methods of each reference.

The sugar feeds are abbreviated: glucose (gluc) and glycerol (gly).

${ }^{3}$ Fold improvements were calculated using titers reported in this table and the base case/wild type reported in each reference. n/a - not applicable; first demonstration of the pathway. 


\footnotetext{
${ }_{5}^{4}$ A 92\% pure octanoate product was achieved using dynamic regulation.

${ }^{5}$ Some of the fatty acids produced contained a saturated bond.

${ }^{6}$ A 2.37 -fold increase was observed by varying plasmid copy number and an additional 1.46 -fold increase was obtained through RBS tuning.
} 
Table 2: Alcohol production

\begin{tabular}{|c|c|c|c|c|c|c|c|}
\hline Alcohol & $\begin{array}{l}\text { Engineering } \\
\text { approach }\end{array}$ & Organism & Titer $(\mathrm{g} / \mathrm{L})^{1}$ & Yield $^{2}$ & $\begin{array}{c}\text { Fold } \\
\text { improvement }\end{array}$ & $\begin{array}{c}\text { Library } \\
\text { members } \\
\text { screened (\#) }\end{array}$ & Reference \\
\hline \multirow[t]{2}{*}{ Ethanol } & $\begin{array}{l}\text { Growth } \\
\text { screen }\end{array}$ & S. cerevisiae & 34 & $0.42 \mathrm{~g} / \mathrm{g}_{\text {cel }}$ & $1.63^{5}$ & 10,000 & [20] \\
\hline & $\begin{array}{l}\text { Cholorimetric } \\
\text { enzyme } \\
\text { assay, strain } \\
\text { library }\end{array}$ & C. acetobutylicum & 7.2 & $0.144 \mathrm{~g} / \mathrm{g}_{\text {gluc }}$ & 1.37 & 5150 & [7] \\
\hline \multirow[t]{4}{*}{ n-butanol } & $\begin{array}{l}\text { Semi-rational } \\
\text { design }\end{array}$ & C. acetobutylicum & 12.4 & $0.196 \mathrm{~g} / \mathrm{g}_{\text {gluc }}$ & 1.23 & 1620 & {$[10] \bullet$} \\
\hline & $\begin{array}{l}\text { Biosensor } \\
\text { growth } \\
\text { screen, RBS } \\
\text { library }\end{array}$ & E. coli & 0.49 & $0.098 \mathrm{~g} / \mathrm{g}_{\text {gluc }}$ & 1.35 & 960 & {$[14] \bullet$} \\
\hline & Rational & & & & & 130 (rational) & \\
\hline & $\begin{array}{l}\text { design and } \\
\text { directed } \\
\text { evolution }\end{array}$ & E. coli (anaerobic) & 13.4 & $0.157 \mathrm{~g} / \mathrm{g}_{\text {gluc }}$ & 9.5 & $\begin{array}{c}4000 \\
\text { (random) }\end{array}$ & [8] \\
\hline \multirow[t]{2}{*}{ Isobutanol } & $\begin{array}{l}\text { Modular } \\
\text { design, } \\
\text { promoter } \\
\text { design }\end{array}$ & B. subtilis & 3.8 & $\begin{array}{c}- \\
\text { (fed batch) }\end{array}$ & 1.6 & 7 & [43] \\
\hline & $\begin{array}{c}\text { Thermostable } \\
\text { enzyme } \\
\text { prospecting }\end{array}$ & $\begin{array}{c}\text { G. } \\
\text { thermoglucosidasi } \\
\text { us }\end{array}$ & 3.3 & $0.092 \mathrm{~g} / \mathrm{g}_{\text {gluc }}$ & $\mathrm{n} / \mathrm{a}$ & 8 & [59] \\
\hline Isopentanol & $\begin{array}{c}\text { Synergistic } \\
\text { design }\end{array}$ & E. coli & 4.5 & $0.15 \mathrm{~g} / \mathrm{g}_{\text {gluc }}$ & 3.57 & 5 & [55] \\
\hline $\begin{array}{l}\text { 3-methyl-1- } \\
\text { pentanol }^{4}\end{array}$ & $\begin{array}{l}\text { Modular } \\
\text { design, } \\
\text { rational } \\
\text { design }\end{array}$ & E. coli & 0.79 & $0.040 \mathrm{~g} / \mathrm{g}_{\text {gluc }}$ & 132 & 14 & {$[40]$} \\
\hline
\end{tabular}




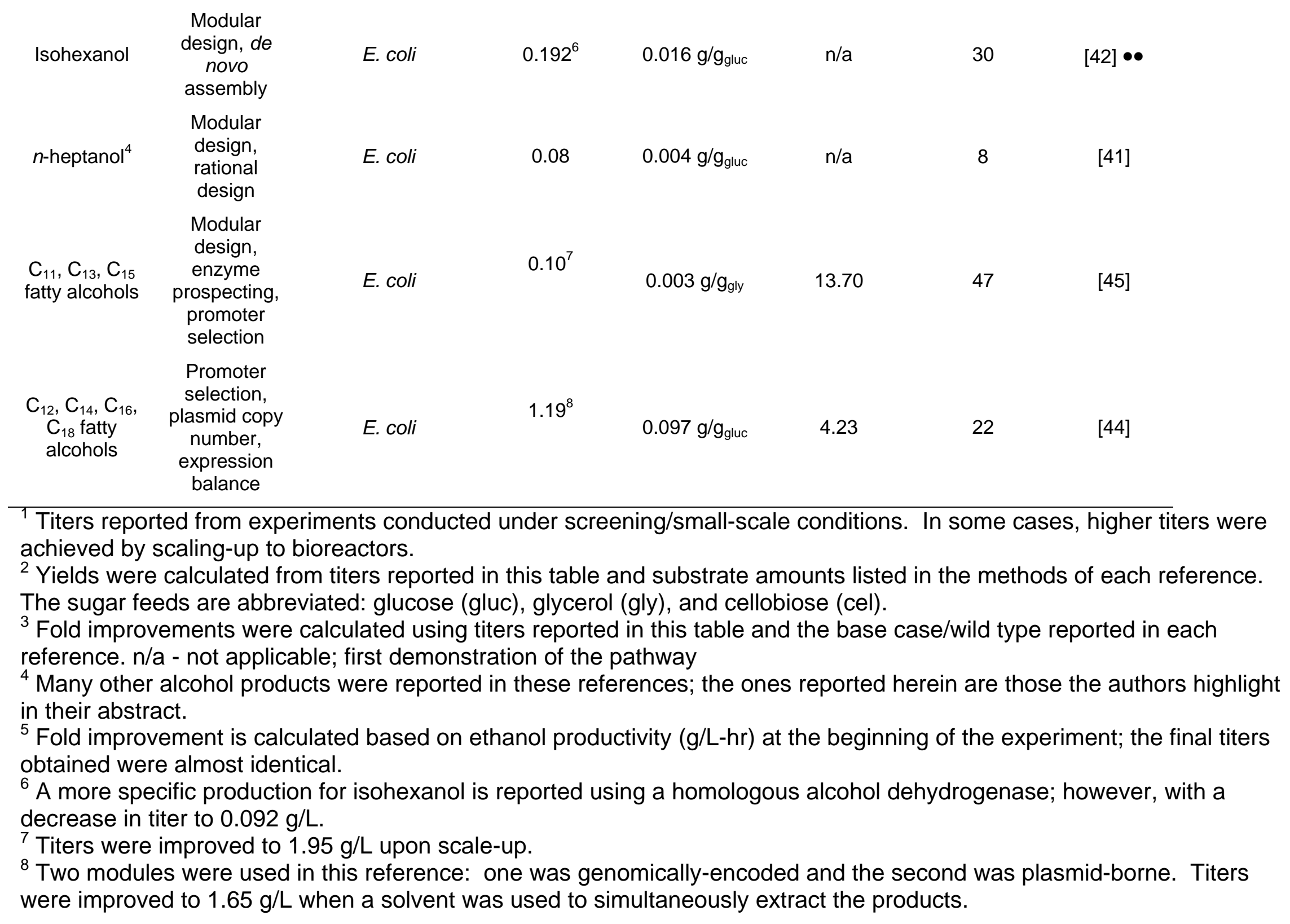




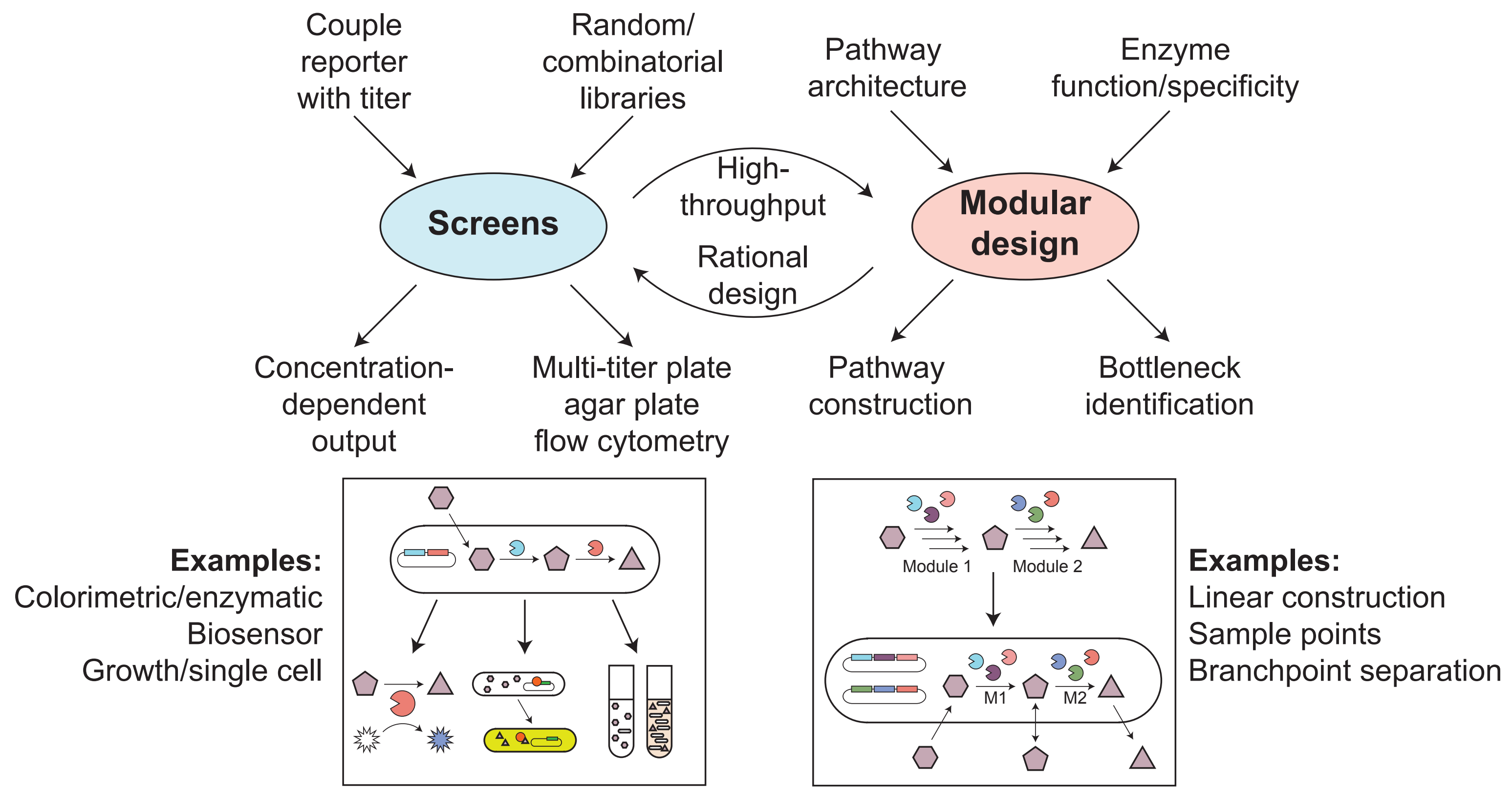

Linear construction

Sample points

Branchpoint separation

\section{Figure 1. Boock et. al. Current Op in Biotech}




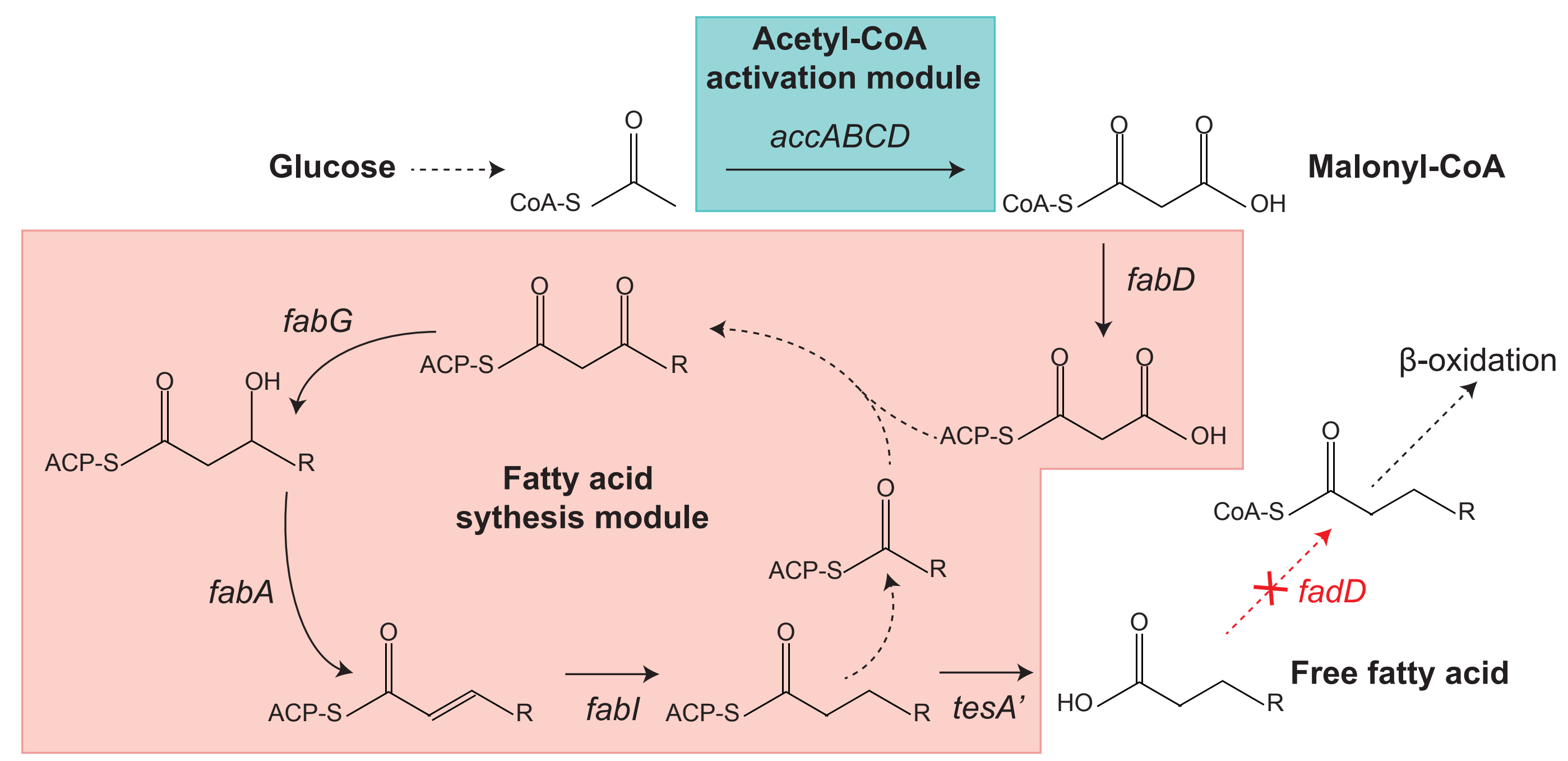

Modular design

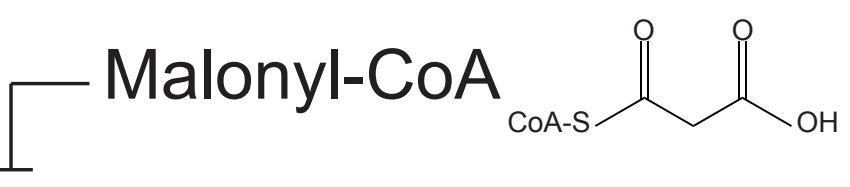

ACA module:

(upstream)

FapR

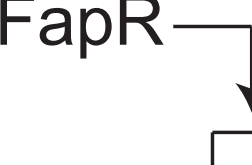

FAS module: (downstream)

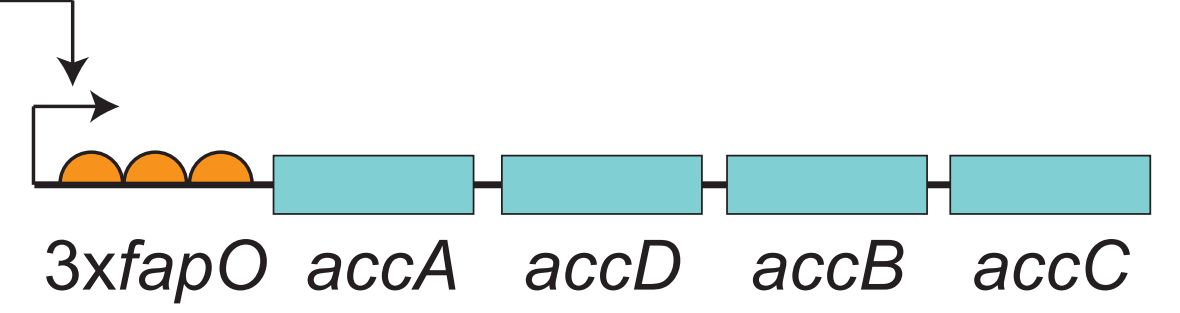

- Malonyl-CoA
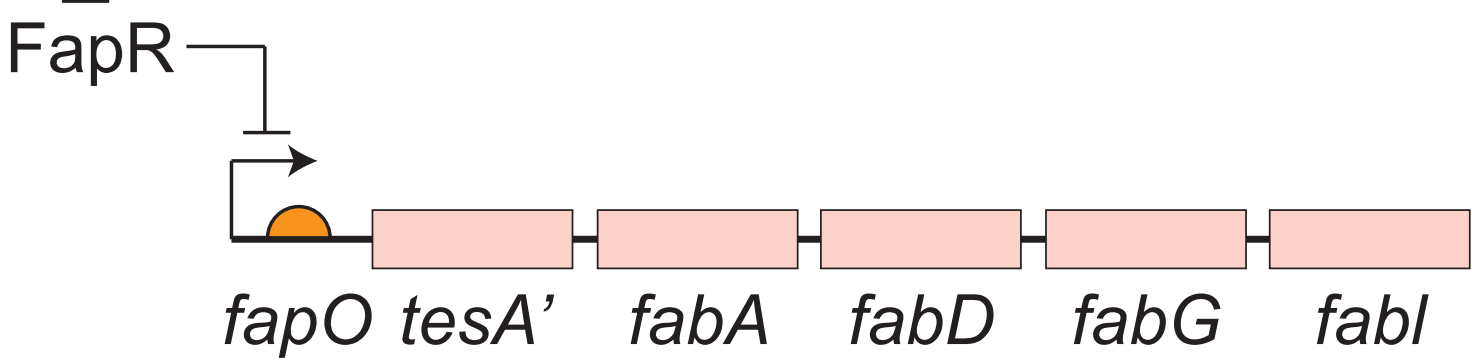

Biosensor output

[Malonyl-CoA]

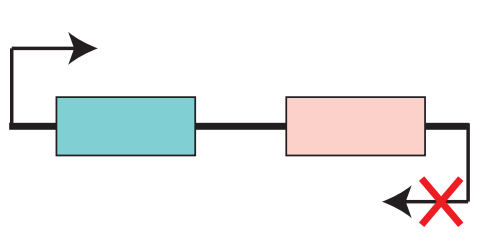

Glucose

$\stackrel{\downarrow}{\downarrow}$

娄

Free fatty acid

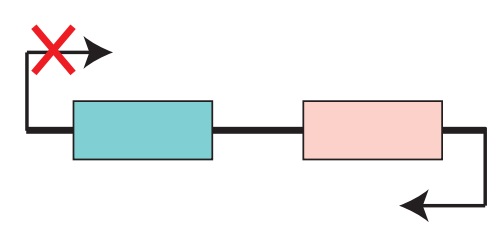

Glucose

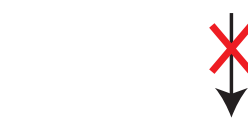

Malonyl-CoA

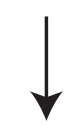

Free fatty acid

Figure 2. Boock et. al. Current Op in Biotech 


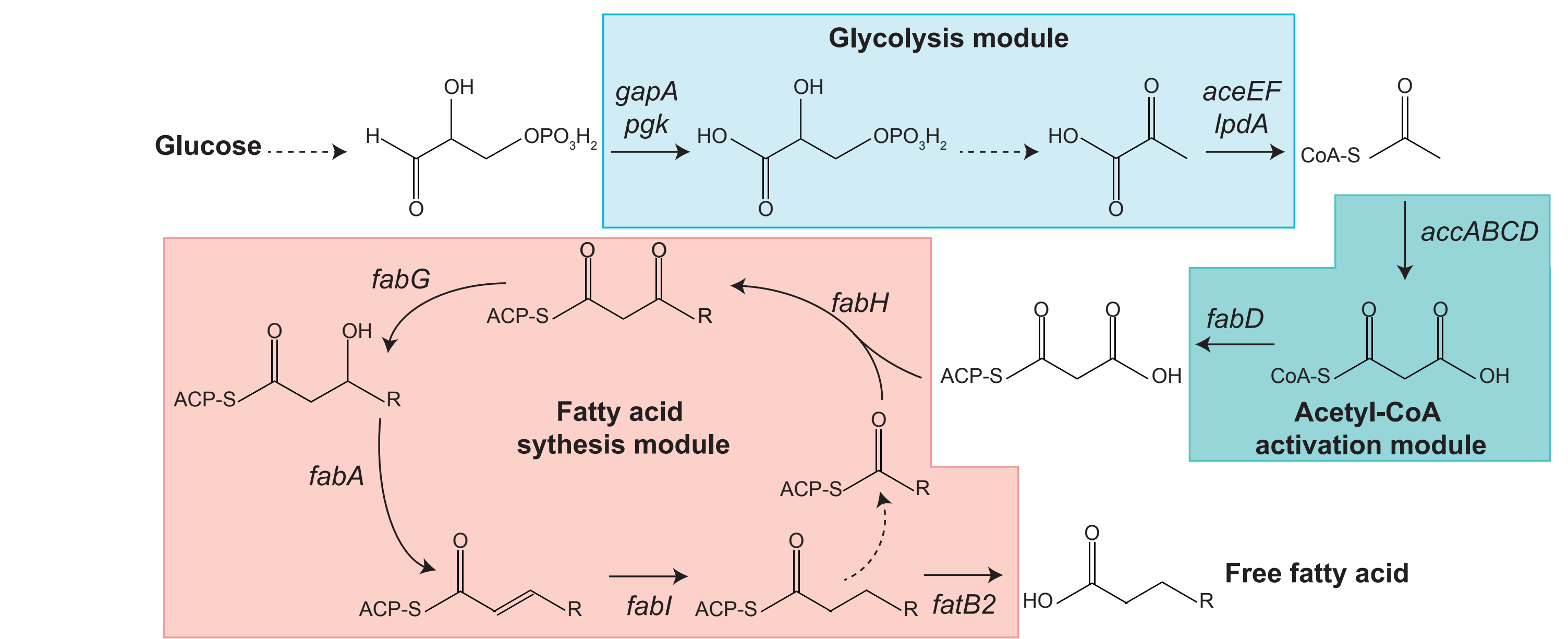

Modular design

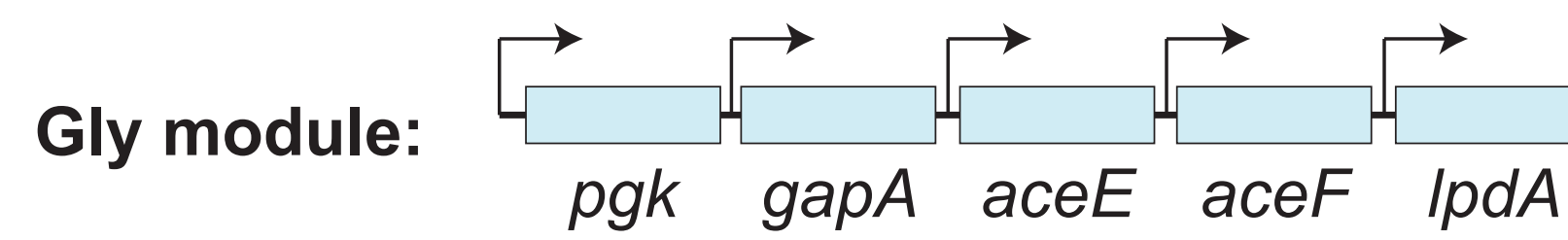

ACA module:

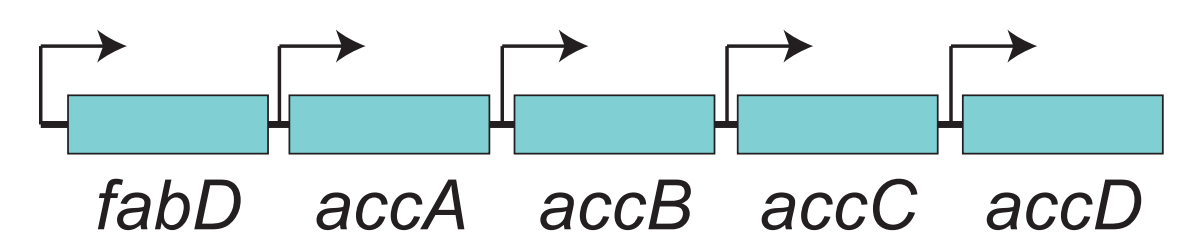

FAS module:

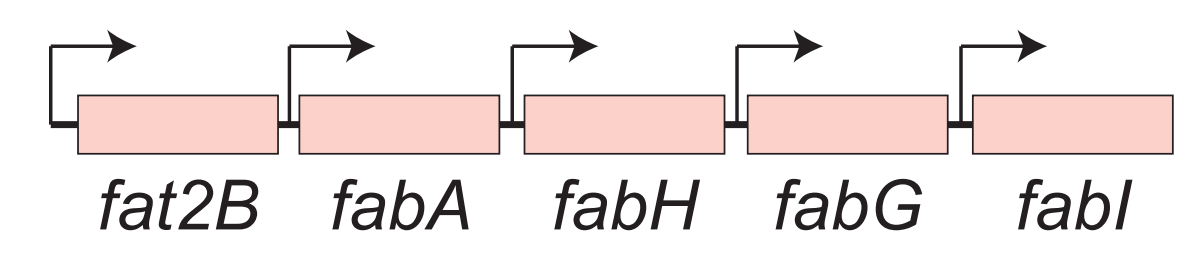

Vary plasmid copy number

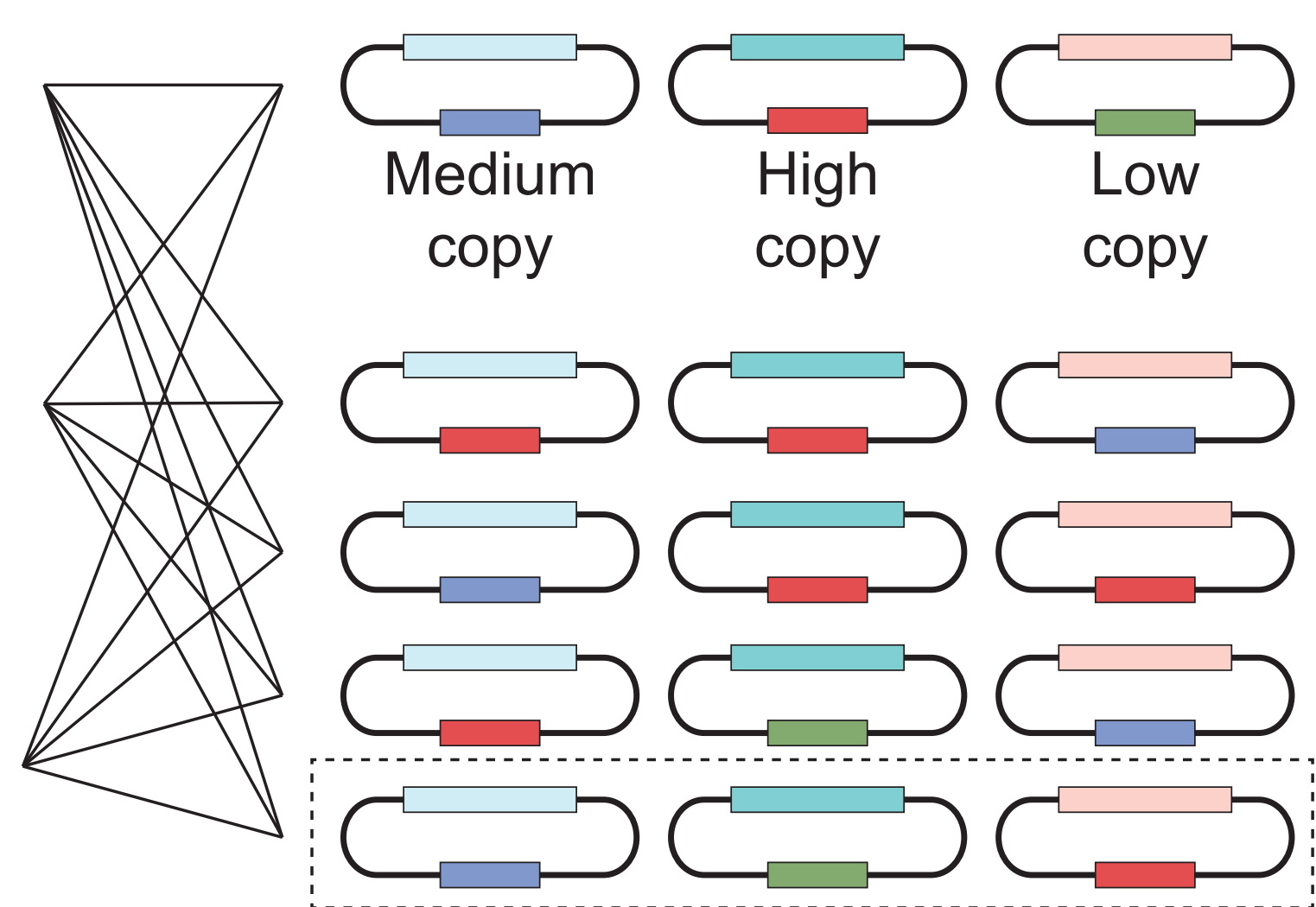

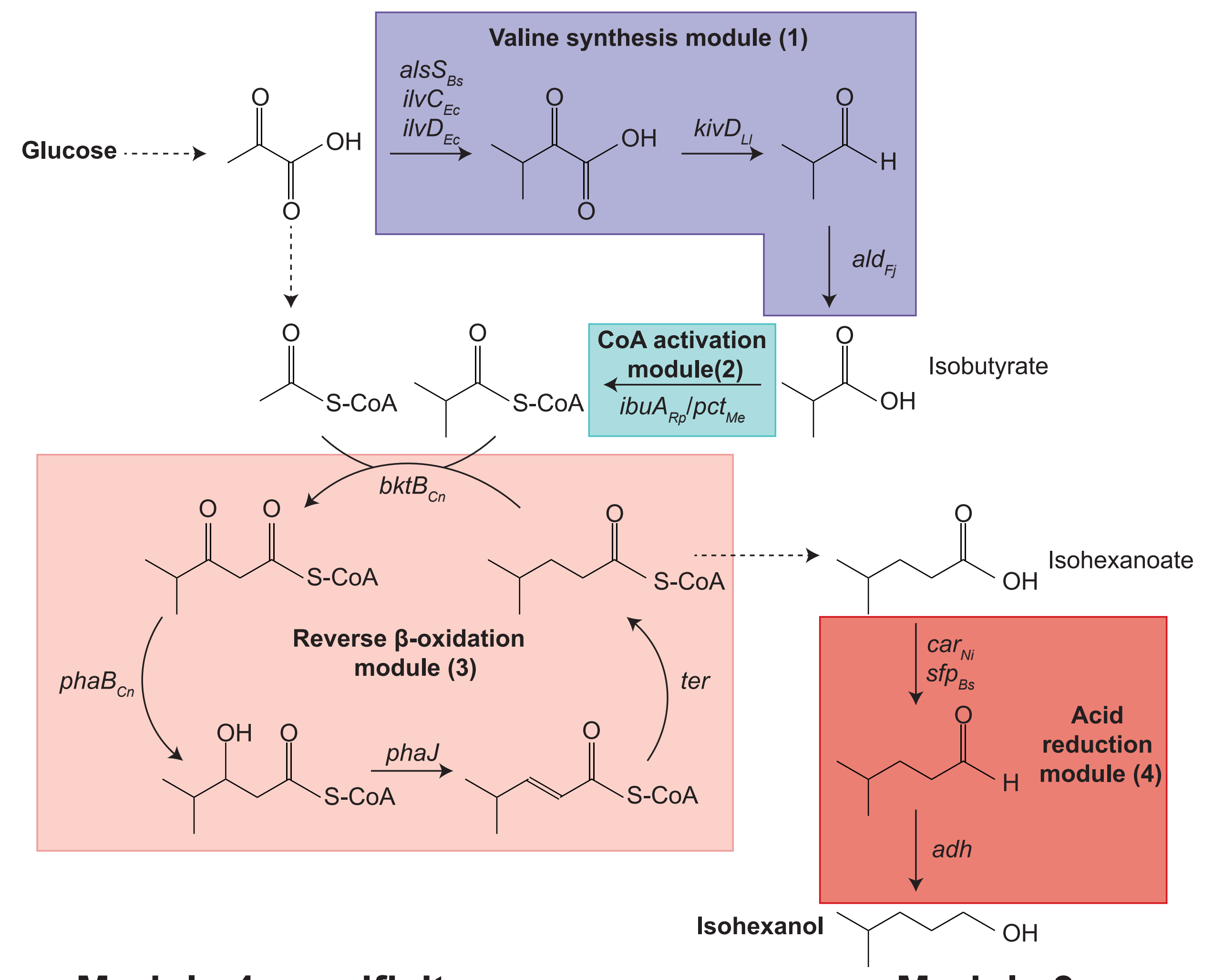

Module 4 specificity

Substrates:

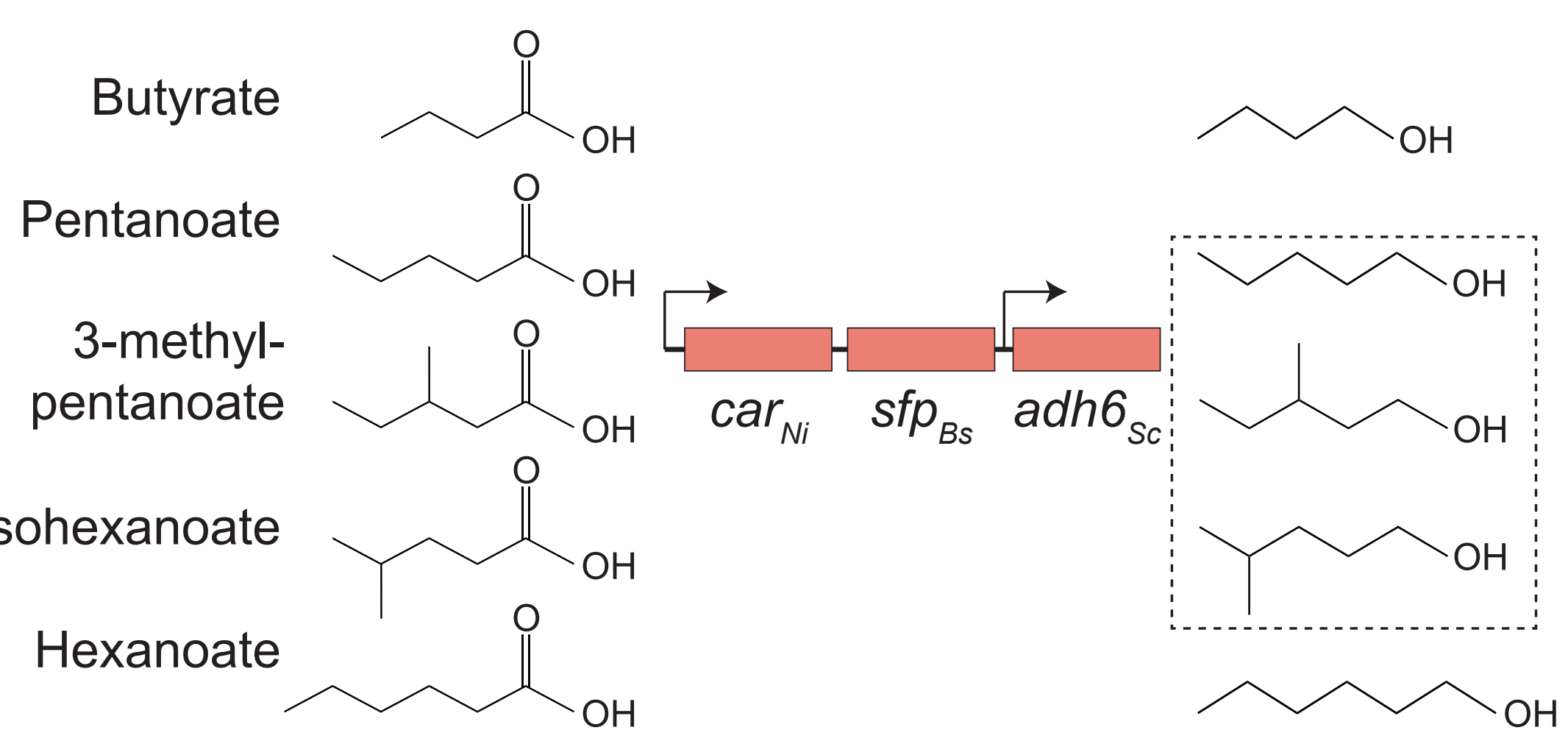

Module 3 enzyme selection

ter variants:

phaJ variants:

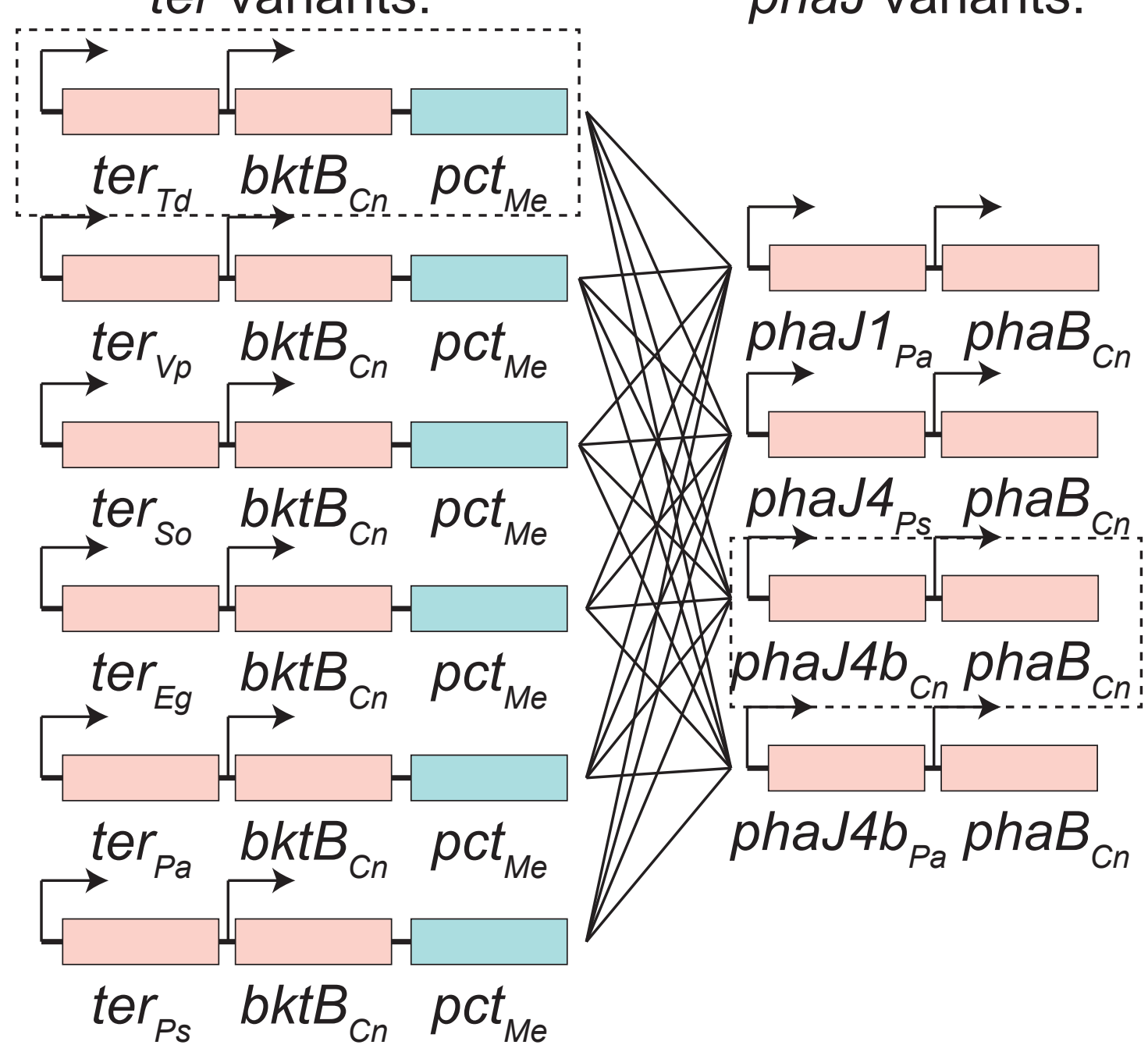

Figure 3. Boock et. al. Current Op in Biotech 